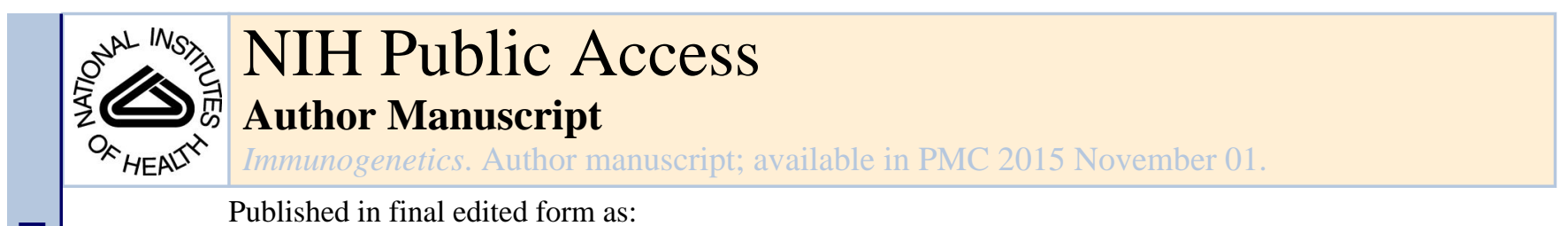

Published in final edited form as:

Immunogenetics. 2014 November ; 66(11): 663-669. doi:10.1007/s00251-014-0796-z.

\title{
Single-nucleotide polymorphism associations in common with immune responses to measles and rubella vaccines
}

\author{
Inna G. Ovsyannikova, \\ Mayo Clinic Vaccine Research Group, Mayo Clinic, Guggenheim 611C, 200 1st Street S.W., \\ Rochester, MN 55905, USA \\ Program in Translational Immunovirology and Biodefense, Mayo Clinic, Rochester, MN 55905, \\ USA
}

Hannah M. Salk,

Mayo Clinic Vaccine Research Group, Mayo Clinic, Guggenheim 611C, 200 1st Street S.W., Rochester, MN 55905, USA

Beth R. Larrabee,

Department of Health Sciences Research, Mayo Clinic, Rochester, MN 55905, USA

V. Shane Pankratz, and

Department of Health Sciences Research, Mayo Clinic, Rochester, MN 55905, USA

Gregory A. Poland

Mayo Clinic Vaccine Research Group, Mayo Clinic, Guggenheim 611C, 200 1st Street S.W., Rochester, MN 55905, USA

Department of Pediatric and Adolescent Medicine, Mayo Clinic, Rochester, MN 55905, USA

Program in Translational Immunovirology and Biodefense, Mayo Clinic, Rochester, MN 55905, USA

\section{Abstract}

Single-nucleotide polymorphisms (SNPs) in candidate immune response genes were evaluated for associations with measles- and rubella-specific neutralizing antibodies, interferon (IFN)- $\gamma$, and interleukin (IL)-6 secretion in two separate association analyses in a cohort of healthy immunized subjects. We identified six SNP associations shared between the measles-specific and rubellaspecific immune responses, specifically neutralizing antibody titers (DDX58), secreted IL-6 (IL1ORB, IL12B), and secreted IFN- $\gamma$ (IFNAR2, TLR4). An intronic SNP (rs669260) in the antiviral innate immune receptor gene, DDX58, was significantly associated with increased

(C) Springer-Verlag Berlin Heidelberg 2014

poland.gregory@mayo.edu.

Conflict of interest Dr. Poland is the chair of a Safety Evaluation Committee for novel non-rubella investigational vaccine trials being conducted by Merck Research Laboratories. Dr. Poland offers consultative advice on vaccine development to Merck \& Co. Inc., CSL Biotherapies, Avianax, Sanofi Pasteur, Dynavax, Novartis Vaccines and Therapeutics, PAXVAX Inc., and Emergent Biosolutions. Drs. Poland and Ovsyannikova hold two patents related to measles and vaccinia peptide research. These activities have been reviewed by the Mayo Clinic Conflict of Interest Review Board and are conducted in compliance with Mayo Clinic Conflict of Interest policies. This research has been reviewed by the Mayo Clinic Conflict of Interest Review Board and was conducted in compliance with Mayo Clinic Conflict of Interest policies. 
neutralizing antibody titers for both measles and rubella viral antigens post-MMR vaccination $(p$ values 0.02 and 0.0002, respectively). Significant associations were also found between IL1ORB (rs2284552; measles study $p$ value 0.006 , rubella study p value 0.00008 ) and IL12B (rs2546893; measles study $p$ value 0.005 , rubella study $p$ value 0.03 ) gene polymorphisms and variations in both measles- and rubella virus-specific IL-6 responses. We also identified associations between individual SNPs in the IFNAR2 and TLR4 genes that were associated with IFN- $\gamma$ secretion for both measles and rubella vaccine-specific immune responses. These results are the first to indicate that there are SNP associations in common across measles and rubella vaccine immune responses and that SNPs from multiple genes involved in innate and adaptive immune response regulation may contribute to the overall human antiviral response.

\section{Keywords}

SNPs; Polymorphisms; Rubella vaccine; Measles vaccine; Neutralizing antibodies; Cytokines

\section{Introduction}

The measles-mumps-rubella (MMR) vaccine, developed in the early 1970s, has been used globally to immunize and protect children against these viral diseases (Carter and Campbell 1993). Although the MMR vaccine has successfully prevented millions of cases of measles, mumps, and rubella infection, heterogeneity of vaccine-induced immune responses exists, causing some individuals to develop exceptional immunity against these viruses while others develop suboptimal immunity (Poland et al. 2007). Several factors are responsible for these interindividual variations in immune response to MMR vaccine, including genetic differences (Poland et al. 2008). In our previous studies, we identified several associations between genotype and phenotypic immune response to both measles vaccine and rubella vaccine (Haralambieva et al. 2011a; Ovsyannikova et al. 2010a; Ovsyannikova et al. 2010b; Ovsyannikova et al. 2011b). Because immunization against measles and rubella is provided by one vaccine, finding genetic associations shared between measles-specific and rubellaspecific immune responses is of great interest. Previous studies have identified SNPs significantly associated with either measles-specific vaccine response or rubella-specific vaccine response; however, this is the first study that identifies SNPs significantly associated with responses to both the measles virus and rubella virus components of the MMR vaccine. In this report, we identify several single-nucleotide polymorphisms (SNPs) in candidate immune response genes that are significantly associated with immune response outcomes to both measles and rubella vaccines. These results may direct future functional studies to determine the mechanistic consequences of common genetic variations on immune response variations and could guide new vaccine design.

\section{Materials and methods}

\section{Study subjects and vaccination}

Details of this study's recruitment and study subjects have been previously described elsewhere (Haralambieva et al. 2010; Ovsyannikova et al. 2010a; Ovsyannikova et al. 2011b; Ovsyannikova et al. 2004; Ovsyannikova et al. 2005). This cohort, originally used as 
part of our earlier MMR vaccine studies (subjects recruited in 2001-2007), consisted of 764 healthy children from Rochester, MN, ranging in age from 11 to 18 years. In this cohort $(n=764)$, we measured immune response to measles vaccination (measles vaccine [MV] study). All of these individuals were measured for immune response to rubella vaccination. In 2008-2009, we expanded the cohort to include an additional 288 subjects for studies of immune responses to rubella vaccine (rubella vaccine [RV] study), resulting in a group of 1,052 healthy individuals ranging in age from 11 to 22 years who were measured for rubella vaccine immune responses. All subjects had written records of having received two doses of MMR vaccine. The institutional review board of the Mayo Clinic granted permission for the study.

\section{Antibody measurement}

MV study-As previously described, measles-specific neutralizing antibody titers were measured via plaque reduction microneutralization assay (PRMN) (Haralambieva et al. 2008).

RV study-Rubella-specific neutralizing antibody titers were measured using a modified ICA-based neutralization assay (sICNA), and results were reported as the neutralizing titer $\left(\mathrm{NT}_{50}\right)$. This method has been previously described elsewhere (Lambert et al. 2014).

\section{Secreted cytokine measurement}

MV study-Measurement of measles-specific interleukin (IL)- 6 and interferon (IFN)- $\gamma$ secreted cytokines were completed by enzyme-linked immunosorbent assays (ELISA), and detailed protocols have been published elsewhere (Haralambieva et al. 2011a; Haralambieva et al. 2011b; Ovsyannikova et al. 2011a; Ovsyannikova et al. 2013; Ovsyannikova et al. 2011b). Briefly, peripheral blood mononuclear cells (PBMCs) were stimulated with the Edmonston B vaccine strain of measles virus with an MOI of 1.0 and an incubation time of $72 \mathrm{~h}$ for both IL-6 and IFN- $\gamma$.

RV study-Rubella-specific IL- 6 and IFN- $\gamma$ cytokine secretion was measured by ELISA, which has been formerly detailed (Dhiman et al. 2010; Lambert et al. 2013; Ovsyannikova et al. 2009). In short, PBMCs were stimulated with rubella virus (W-Therien strain) with an MOI of 5.0 and incubated for 24 and $48 \mathrm{~h}$ for IL-6 and IFN- $\gamma$, respectively.

\section{Candidate gene SNP genotyping}

The description of the tagging SNP selection strategies and genotyping methods has been previously described (Haralambieva et al. 2011a; Ovsyannikova et al. 2011a; Ovsyannikova et al. 2011b). In brief, candidate genes were selected based upon their relevance in MMR vaccine response, as indicated by the literature, public databases, and our own data. SNPs within candidate genes, $5 \mathrm{~kb}$ upstream and downstream for each candidate gene, were chosen based on the linkage disequilibrium (LD) tagSNP selection algorithm [24] from the Hapmap Phase II (http://www.hapmap.org), Seattle SNPs (http://pga.mbt.washington.edu/), and NIEHS SNPs (http://egp.gs.washington.edu/), with SNP minor allele frequencies $>0.05$, LD threshold of $r^{2}>0.90$. Of the candidate SNPs assessed for rubella-specific (Haralambieva et al. 2014; Pankratz et al. 2010) and measles-specific associations (Kennedy et al. 2012), a 
total of 93 SNPs had been studied in common between measles and rubella studies, and only these SNPs were incorporated into this study.

\section{Statistical analysis}

Our goal was to determine whether there were individual genetic variants with shared associations across multiple virus-specific immune response phenotypes. We have reported many of these associations previously, and the analytical methods used to assess the associations are outlined in those publications (Haralambieva et al. 2011a; Ovsyannikova et al. 2010b; Ovsyannikova et al. 2012; Ovsyannikova et al. 2011b). To assess genetic associations with neutralizing antibody for which a single observation was obtained per subject, simple linear regression models were employed after logarithmic transformation of antibody levels. All other outcomes considered were evaluated with repeated measures approaches in which the multiple observations obtained per subject were modeled simultaneously. In these analyses, we used an unstructured within-person variancecovariance matrix to account for within-subject correlations. Spearman correlations were computed for all possible combinations of the considered outcomes. The primary genetic model used to assess significance assumed an ordinal trend across SNP genotypes ordered by the number of copies of the minor allele. Models were structured such that a test of the genotype by stimulation status interaction assessed the effect of genotype on the average difference between stimulated and unstimulated PBMC samples. Our tests of association in each of these investigations adjusted for a number of potentially important covariates, including age at vaccination, sex, and time between most recent vaccination and study participation. We compared the magnitude of the $p$ values observed for the measured measles-and rubella-specific immune responses on a SNP-by-SNP basis and identified those genetic variants that achieved statistical significance in both at the $p<0.05$ level. Association results for 93 SNPs were compared between measurements made for three distinct phenotypes measured specifically for measles and rubella vaccine immune responses. With the requirement that the SNPs have $p<0.05$ for the phenotypes for both pathogens, the effective type I error per SNP was 0.0025. To control the experiment-wise type I error rate, we used an exact binomial test to assess whether the observed number of SNPs with shared associations was greater than the expected number under the null hypothesis that there were no common SNP associations. Summaries of the measures of virus-specific immune phenotypes were obtained for the genotypes of the SNPs, which were thus identified, as noted in our previously published work (Haralambieva et al. 2011a; Ovsyannikova et al. 2010a; Ovsyannikova et al. 2010b; Ovsyannikova et al. 2011b).

\section{Results Demographics}

The measured neutralizing antibody titers and secreted cytokine responses varied between the MV and RV studies due to differences in methodology. For an overview of subject demographics, see Table 1. MV study: Of 764 subjects, $55.9 \%$ were male and $44.1 \%$ were female. Caucasian-American subjects comprised $80.6 \%$ of the cohort and $11.6 \%$ identified as African-American. Neutralizing antibody titers were measured on 763 individuals, and the median response was 844.0 (IQR 418.0, 1752.0). Secreted IL-6 and IFN- $\gamma$ were 
successfully measured in 756 subjects. The median of secreted IL-6 was $354.6 \mathrm{ng} / \mu \mathrm{l}$ (IQR, 248.5-461.4), whereas the median of secreted IFN- $\gamma$ in this cohort of study subjects was $67.4 \mathrm{ng} / \mu \mathrm{l}(\mathrm{IQR}, 35.2-120.5)$.

RV study: Included in this study were 1,052 subjects, and of these, $54.9 \%$ were male and $45.1 \%$ were female; $84.9 \%$ of subjects identified as Caucasian-American, whereas $8.2 \%$ identified as African-American. Neutralizing antibody titers were measured in 1,042 subjects with a median response of 57.4 (IQR, 34.9, 95.8). IL-6 cytokine measurement was completed on 1,001 subjects, and a median of 3,595.6 ng/ $\mu \mathrm{l}(\mathrm{IQR}, 3,032.0-4,008.4)$ was observed. Secreted IFN- $\gamma$ was measured on 982 subjects with a median of $6.2 \mathrm{ng} / \mu \mathrm{l}$ (IQR, 1.5-20.2). Measles- and rubella virus-specific neutralizing antibody titers and secreted cytokine levels (IL-6 and IFN- $\gamma$ ) were remarkably different between two studies.

Neutralizing antibody titers $(p<0.0001)$ and secreted IFN- $\gamma$ levels $(p<0.0001)$ were significantly higher in the MV study than in the RV study. In contrast, secreted IL-6 levels $(p<0.0001)$ were significantly lower in the MV study than in the RV study. There was no evidence of a correlation between measles- and rubella-specific IL- 6 secretion $(r=0.010$, $p=0.80, n=695$ subjects $)$ or measles- and rubella-specific IFN- $\gamma$ secretion $(r=0.079, p=0.04$, $n=677$ subjects); however, there was a slight correlation between measles- and rubellaspecific neutralizing antibody titers $(r=0.214, p<0.0001, n=718$ subjects $)$.

A total of six SNPs were found to be associated both with measles- and rubella-specific immune responses to MMR vaccine. The binomial test comparing this number with the expected number under the null hypothesis, given 279 comparisons made at an effective $p$ value per comparison of 0.0025 , resulted in a $p$ value of $8.5 \times 10^{-5}$. Therefore, we can conclude that the number of SNPs with common associations between measles and rubella phenotypes is greater than what would be expected to occur under the null hypothesis of no common SNP associations.

\section{Associations between SNPs and neutralizing antibody titers}

We identified an intronic SNP, rs669260, in the DDX58 gene that was significantly associated with neutralizing antibody titers to MV and to RV ( $p$ values 0.0198 and 0.0002 , respectively). There was an increasing trend in both measles- and rubella-specific neutralizing antibody titers. Although, the magnitude of effect was higher for MVand the genetic model favored a dominant mode of effect for RV (Table 2), both suggested that the presence of the minor allele was associated with higher neutralizing antibody levels.

\section{Associations between SNPs and IL-6 secretion}

Two significant SNP associations were observed in common with secreted IL-6 in both the MVand RV studies: rs2284552 in the interleukin-10 receptor beta (IL10RB) gene and rs2546893 in the IL12B gene. The $p$ values for these associations were 0.0057 and 0.0056 for $\mathrm{MV}$ and 0.00008 and 0.0294 for RV. The minor allele variant (AA) in both the rs2284552 SNP and the rs2546893 SNP was associated with heightened IL-6 secretion postviral stimulation by both MV and RV (Table 2). 


\section{Associations between SNPs and IFN- $\gamma$ secretion}

We identified three SNPs significantly associated with measles- and rubella-specific secreted IFN- $\gamma$ response: rs 17860160 in the IFNAR2 gene (MV $p$ value $0.0336, \mathrm{RV} p$ value 0.0011 ), rs 2770150 in the TLR4 gene (MV $p$ value 0.0118 , RV $p$ value 0.0175 ), and rs 2834160 in the IFNAR2 gene (MV $p$ value 0.0261 , RV $p$ value 0.0013 ). Increasing copies of the minor allele of the rs17860160 SNP was associated with decreasing trends of secreted IFN $-\gamma$ in both studies. Conversely, increasing numbers of the minor allele of the rs 2770150 SNP were associated with an increasing trend in IFN- $\gamma$ secretion in both studies. Subjects in both the MV and RV studies with increasing numbers of the minor allele of the rs 2834160 SNP tended to secrete lower levels of IFN- $\gamma$ (Table 2).

\section{Discussion}

Associations between post-vaccination immune responses and genetic polymorphisms have been explored in an attempt to explain the interindividual variation in immune responses to single vaccines; however, SNPs associated with immune response outcomes to multiple vaccines have not been widely studied, making this study the first of its kind. In order to broaden scientific knowledge in this area, our study explored candidate gene SNPs associated with immune response outcomes to both measles vaccine and rubella vaccine. Using the aforementioned statistical approach, we identified polymorphisms associated with measles vaccine-specific and rubella vaccine-specific immune response outcomes (i.e., neutralizing antibody titers, secreted IL-6, and IFN- $\gamma$ response), including SNPs in the DDX58, IL1ORB, IL12B, IFNAR2, and TLR4 genes.

We detected an association between a polymorphism in the DDX58 gene (rs669260) and neutralizing antibody titers in both measles and rubella vaccine studies. The DDX58 gene encodes retinoic acid inducible gene I (RIG-1), which functions to sense cytoplasmic viral nucleic acids during viral infection (Hornung et al. 2006; Ovsyannikova et al. 2010a). RIG-1 has been shown to inhibit measles virus replication by way of retinoid induction, primarily vitamin A, while also depending on the expression of IRF-1 and the production of interferons (Soye et al. 2011). The relationship between DDX58 (RIG-1) and rubella virus has been less widely studied; however, the minor allele of the DDX58 gene SNP rs669260 was associated with higher rubella-specific neutralizing antibody titers, suggesting that this polymorphism may also play a role in eliminating rubella viral infection.

Additionally, we identified two SNPs associated with measles- and rubella-specific IL-6 secretion, including one intronic SNP in the IL10RB gene (rs2284552) and one intronic SNP in the IL12B gene (rs2546893). The expression of IL10RB, in conjunction with IL10RA, is critical for the induction of IL-10 signaling, which has been shown to inhibit cytokine secretion, particularly IL-6, in monocytes by inhibiting the IL6 gene transcription factor activator protein-1 (AP-1) (Dokter et al. 1996). Polymorphisms in the IL10RB gene may disrupt the homeostasis of the IL-10 signaling pathway, resulting in altered levels of IL-6 production, as seen in this study. This specific IL1ORB gene SNP was also significantly associated with IL-6 secretion when analysis was performed on the Caucasian-American subset of the study subjects. Interestingly, the major allele variant (CC) was associated with enhanced IL-6 secretion ( $p=0.05$ ) post-measles virus stimulation, and the heterozygous 
allele variant (CA) was associated with enhanced IL-6 secretion $(p=0.007)$ after rubella virus stimulation in the Caucasian-American subset (data not shown), which differs from the results when analysis was completed on the entire cohort.

Also significantly associated with IL-6 secretion post-MMR vaccination was the rs 2546893 SNP in the $I L 12 B$ gene. The $I L 12 B$ gene encodes the IL-12p40 subunit of IL-12 and IL-23, both heterodimeric cytokines that work cooperatively to control cellular immune responses during antigenic stimulation. IL-12 plays a crucial role in the differentiation of Tcells into the Th1 cells, while IL-23 activates memory T cells to produce proinflammatory cytokines, such as IL-6 and IL-17 (Langrish et al. 2004; Yen et al. 2006). Interestingly, the minor allele variant (AA) was significantly associated with an enhanced IL-6 response to both measles and rubella virus stimulation post-MMR vaccination.

Lastly, we detected three SNPs significantly associated with secreted IFN- $\gamma$ after measles and rubella vaccination, including two SNPs in the IFNAR2 gene (rs17860160 and rs2834160) and an intergenic SNP in the TLR4 gene (rs2770150). The IFNAR2 gene codes for a transmembrane receptor protein specific to type I interferons, such as IFN- $a$ and IFN$\beta$, that generate potent anti-viral responses to viral antigens, such as measles virus and rubella virus (Piehler and Schreiber 1999). The major allele variants for the rs17830160 and rs 2834160 SNPs in the IFNAR2 gene were associated with enhanced IFN- $\gamma$ secretion after measles virus stimulation, while the major allele variant of the rs2834160 SNP and the minor allele of the rs 17860160 SNP were associated with decreasing trends IFN- $\gamma$ secretion after rubella virus stimulation. Additionally, the minor allele variant of the SNP in the TLR4 gene, which encodes toll-like receptor protein 4 and plays a vital role in pathogen recognition and induction of innate immune response pathways via expression of cytokines and co-stimulatory molecules (Kopp and Medzhitov 1999), was associated with greater IFN$\gamma$ secretion than the other variants, especially after measles virus stimulation. The role of TLR4 in the initiation of innate and adaptive immune response has been widely studied (Ovsyannikova et al. 2011b), and other polymorphisms in the TLR4 gene have been correlated with low levels of inflammatory molecules and, therefore, increased risk of severe infection (Kiechl et al. 2002), signifying the importance of functional TLR4 in response to antigenic stimulation. This suggests that vaccines against measles and rubella viruses may use common genes (SNPs), such as the DDX58, IL10RB, IL12B, IFNAR2, and TLR4, and different innate and adaptive immune pathway genes to produce immune responses.

A recent report also analyzed allelic variant commonalities between vaccines by utilizing systematic review and meta-analysis (Posteraro et al. 2014). As a result, four HLA alleles (DRB1*07, DQA1*02:01, DQB1*02:01, and DQB1*03:03) were found to be significantly associated with lower antibody responses to MMR-II, hepatitis B, and influenza vaccines in addition to two HLA alleles (DRB1*13 and DRB1*13:01) associated with high antibody responses (Posteraro et al. 2014). Aside from this study, which focused solely on HLA SNP associations, genome-wide SNP commonalities between vaccines in association with vaccine-specific immune response outcomes have not been widely studied, which is why data identifying these commonalities is of great interest as it may advance our understanding of the mechanisms underlying vaccine immune response, as well as assist in the design of new candidate vaccines. 
There are several strengths and limitations to this study. The recruitment and utilization of a large sample population added to the genetic diversity of the study, enhancing the power of the results, although it should be noted that the available sample sizes were still too small to clearly elucidate the patterns of genetic association. The primary limitation of this study was the comparison between only measles vaccine and rubella vaccine responses. It would be beneficial to compare SNP associations among more vaccines; this would further aid in our understanding of the specific mechanisms underlying vaccine response. We acknowledge that corrections for multiple comparisons were not applied. Therefore, future directions of this study include replication and validation studies.

When measuring humoral and cellular immune responses, we observed statistically significant differences in neutralizing antibody titers (15-fold difference), IL-6 (10-fold difference), and IFN- $\gamma$ (11-fold difference) secretion levels between the MVand RV studies. This may, in part, be due to a combination of the multiple differences in the optimized assay conditions to each antigen noted between two studies. This, in turn, allowed us to more clearly observe the antigen-specific impact of certain SNPs on immune response outcomes to each measles virus and rubella virus separately. Further, a total of 764 and 1,052 subjects were included in analysis for response to measles virus and rubella virus, respectively. All of the 764 subjects in the measles vaccine study were included in the 1,052 subjects of the rubella vaccine study. We found minimal or no correlation between measles and rubella humoral and cellular immune responses following MMR vaccination. Because of the low correlation between measles and rubella vaccine immune responses, it is unlikely that SNP associations observed in common were spuriously driven by commonalities between immune response measures within subjects.

In conclusion, the primary strength of this study is that it is the first major study to analyze commonalities in SNP associations to vaccine-specific immune response to both measles vaccine and rubella vaccine. We found several SNP associations shared in common between measles vaccine response and rubella vaccine response, including SNPs in the DDX58, ILIORB, IL12B, TLR4, and IFNAR2 genes. Our data suggest the possibility that these and other common genetic polymorphisms may be linked to the overall antiviral host response. Replication studies are crucial to evaluate these results and design future studies. Ultimately, these results could potentially inform us about the genetic correlates of protective vaccine immunity and may provide important clues on genetic variants that contribute to altered immune responses to more than one vaccine.

\section{Acknowledgments}

We thank the Mayo Clinic Vaccine Research Group staff and subjects who participated in our studies. We thank Caroline L. Vitse for her help with this manuscript. This work was supported by NIH grants AI33144, R37 AI048793 (which recently received a MERIT Award) and was made possible by the Rochester Epidemiology Project (Grant Number R01 AG034676 from the National Institute on Aging). The content is solely the responsibility of the authors and does not necessarily represent the official views of the National Institutes of Health.

\section{References}

Carter H, Campbell J. Rational use of measles, mumps and rubella (MMR) vaccine. Drugs. 1993; 45:677-683. [PubMed: 7686463] 
Dhiman N, Haralambieva IH, Vierkant RA, Pankratz VS, Ryan E, Jacobson RM, Ovsyannikova IG, Poland GA. Predominant inflammatory cytokine secretion pattern in response to two doses of live rubella vaccine in health vaccines. Cytokine. 2010; 50:24-29. [PubMed: 20117947]

Dokter WH, Koopmans SB, Vellenga E. Effects of IL-10 and IL-4 on LPS-induced transcription factors (AP-1, NF-IL6 and NF-kappa B) which are involved in IL-6 regulation. Leukemia. 1996; 10:1308-1316. [PubMed: 8709636]

Haralambieva IH, Dhiman N, Ovsyannikova IG, Vierkant RA, Pankratz VS, Jacobson RM, Poland GA. 2'-5'-Oligoadenylate synthetase single-nucleotide polymorphisms and haplotypes are associated with variations in immune responses to rubella vaccine. Hum Immunol. 2010; 71:383391. [PubMed: 20079393]

Haralambieva IH, Lambert ND, Ovsyannikova IG, Kennedy RB, Larrabee BR, Pankrantz VS, Poland GA. Associations between single nucleotide polymorphisms in cellular viral receptors and attachment factor-related genes and humoral immunity to ru-bella vaccination. PLoS One. 2014; 9(6):e99997. [PubMed: 24945853]

Haralambieva IH, Ovsyannikova IG, Kennedy RB, Vierkant RA, Pankratz SV, Jacobson RM, Poland GA. Associations between single nucleotide polymorphisms and haplotypes in cytokine and cytokine receptor genes and immunity to measles vaccination. Vaccine. 2011a; 29:7883-7895. [PubMed: 21875636]

Haralambieva IH, Ovsyannikova IG, Umlauf BJ, Vierkant RA, Pankratz SV, Jacobson RM, Poland GA. Genetic polymorphisms in host antiviral genes: associations with humoral and cellular immunity to measles vaccine. Vaccine. 2011b; 29:8988-8997. [PubMed: 21939710]

Haralambieva IH, Ovsyannikova IG, Vierkant RA, Poland GA. Development of a novel efficient fluorescence-based plaque reduction microneutralization assay for measles immunity. Clin Vaccine Immunol. 2008; 15:1054-1059. [PubMed: 18463223]

Hornung V, Ellegast J, Kim S, Brzozka K, Jung A, Kato H, Poeck H, Akira S, Conzelmann KK, Schlee M, Endres S, Hartmann G. 5'-Triphosphate RNA is the ligand for RIG-I. Science. 2006; 314:994-997. [PubMed: 17038590]

Kennedy RB, Ovsyannikova IG, Haralambieva IH, O'Byrne MM, Jacobson RM, Pankratz VS, Poland GA. Multigenic control of measles vaccine immunity mediated by polymorphisms in measles receptor, innate pathway, and cytokine genes. Vaccine. 2012; 30:2159-2167. [PubMed: 22265947]

Kiechl S, Lorenz E, Reindl M, Wiedermann CJ, Oberhollenzer F, Bonora E, Willeit J, Schwartz DA. Toll-like receptor 4 polymorphisms and atherogenesis. N Engl J Med. 2002; 347:185-192. [PubMed: 12124407]

Kopp EB, Medzhitov R. The Toll-receptor family and control of innate immunity. Curr Opin Immunol. 1999; 11:13-18. [PubMed: 10047546]

Lambert ND, Haralambieva IH, Ovsyannikova IG, Larrabee BR, Pankratz VS, Poland GA. Characterization of humoral and cellular immunity to rubella vaccine in four distinct cohorts. Immunol Res. 2013; 58:1-8. [PubMed: 24375276]

Lambert ND, Pankratz VS, Larrabee BR, Ogee-Nwankwo A, Chen MH, Icenogle JP, Poland GA. High-throughput assay optimization and statistical interpolation of rubella-specific neutralizing antibody titers. Clin Vaccine Immunol. 2014; 21:340-346. [PubMed: 24391140]

Langrish CL, McKenzie BS, Wilson NJ, de Waal MR, Kastelein RA, Cua DJ. IL-12 and IL-23: master regulators of innate and adaptive immunity. Immunol Rev. 2004; 202:96-105. [PubMed: 15546388]

Ovsyannikova IG, Dhiman N, Haralambieva IH, Vierkant RA, O'Byrne MM, Jacobson RM, Poland GA. Rubella vaccine-induced cellular immunity: evidence of associations with polymorphisms in the Toll-like, vitamin A and D receptors, and innate immune response genes. Hum Genet. 2010a; 127:207-221. [PubMed: 19902255]

Ovsyannikova IG, Haralambieva IH, Dhiman N, O'Byrne MM, Pankratz VS, Jacobson RM, Poland GA. Polymorphisms in the vitamin A receptor and innate immunity genes influence the antibody response to rubella vaccination. J Infect Dis. 2010b; 201:207-213. [PubMed: 20001730]

Ovsyannikova IG, Haralambieva IH, Vierkant RA, O'Byrne MM, Jacobson RM, Poland GA. The association of CD46, SLAM, and CD209 cellular receptor gene SNPs with variations in measles 
vaccine-induced immune responses - a replication study and examination of novel polymorphisms. Hum Hered. 2011a; 72:206-223. [PubMed: 22086389]

Ovsyannikova IG, Haralambieva IH, Vierkant RA, O'Byrne MM, Jacobson RM, Poland GA. Effects of vitamin A and D receptor gene polymorphisms/haplotypes on immune responses to measles vaccine. Pharmacogenet Genomics. 2012; 22:20-31. [PubMed: 22082653]

Ovsyannikova IG, Haralambieva IH, Vierkant RA, O'Byrne MM, Poland GA. Associations between polymorphisms in the antiviral TRIM genes and measles vaccine immunity. Hum Immunol. 2013; 74:768-774. [PubMed: 23416095]

Ovsyannikova IG, Haralambieva IH, Vierkant RA, Pankratz VS, Poland GA. The role of polymorphisms in toll-like receptors and their associated intracellular signaling genes in measles vaccine immunity. Hum Genet. 2011b; 130:547-561. [PubMed: 21424379]

Ovsyannikova IG, Jacobson RM, Vierkant RA, Jacobsen SJ, Pankratz VS, Poland GA. The contribution of HLA class I antigens in immune status following two doses of rubella vaccination. Hum Immunol. 2004; 65:1506-1515. [PubMed: 15603879]

Ovsyannikova IG, Jacobson RM, Vierkant RA, Jacobsen SJ, Pankratz VS, Poland GA. Human leukocyte antigen class II alleles and rubella-specific humoral and cell-mediated immunity following measles-mumps-rubella-II vaccination. J Infect Dis. 2005; 191:515-519. [PubMed: 15655774]

Ovsyannikova IG, Ryan JE, Vierkant RA, O'Byrne MM, Jacobson RM, Poland GA. Influence of host genetic variation on rubella-specific $\mathrm{T}$ cell cytokine responses following rubella vaccination. Vaccine. 2009; 27:3359-3366. [PubMed: 19200845]

Pankratz VS, Vierkant RA, O'Byrne MM, Ovsyannikova IG, Poland GA. Associations between SNPs in candidate immune-relevant genes and rubella antibody levels: a multigenic assessment. BMC Immunol. 2010; 11:48. [PubMed: 20923569]

Piehler J, Schreiber G. Mutational and structural analysis of the binding interface between type I interferons and their receptor Ifnar2. J Mol Biol. 1999; 294:223-237. [PubMed: 10556041]

Poland GA, Ovsyannikova IG, Jacobson RM. Vaccine immunogenetics: bedside to bench to population. Vaccine. 2008; 26:6183-6188. [PubMed: 18598732]

Poland GA, Ovsyannikova IG, Jacobson RM, Smith DI. Heterogeneity in vaccine immune response: the role of immunogenetics and the emerging field of vaccinomics. Clin Pharmacol Ther. 2007; 82:653-664. [PubMed: 17971814]

Posteraro B, Pastorino R, Di Giannantonio P, Ianuale C, Amore R, Ricciardi W, Boccia S. The link between genetic variation and variability in vaccine responses: systematic review and metaanalyses. Vaccine. 2014; 32:1661-1669. [PubMed: 24513009]

Soye KJ, Trottier C, Richardson CD, Ward BJ, Miller WH Jr. RIG I is required for the inhibition of measles virus by retinoids. PLoS One. 2011; 6:e22323. [PubMed: 21811588]

Yen D, Cheung J, Scheerens H, Poulet F, McClanahan T, McKenzie B, Kleinschek MA, Owyang A, Mattson J, Blumenschein W, Murphy E, Sathe M, Cua DJ, Kastelein RA, Rennick D. IL-23 is essential for T cell-mediated colitis and promotes inflammation via IL-17 and IL-6. J Clin Investig. 2006; 116:1310-1316. [PubMed: 16670770] 
Table 1

Demographic and immunological characteristics of the measles vaccine and rubella vaccine study subjects

\begin{tabular}{|c|c|c|}
\hline & Measles vaccine study $(N=764)$ & Rubella vaccine study $(N=1,052)$ \\
\hline \multicolumn{3}{|l|}{ Gender } \\
\hline Male & $427(55.9 \%)$ & $578(54.9 \%)$ \\
\hline Female & $337(44.1 \%)$ & $474(45.1 \%)$ \\
\hline \multicolumn{3}{|l|}{ Race } \\
\hline American-Indian, Alaska Native & $2(0.3 \%)$ & $4(0.4 \%)$ \\
\hline Asian, Hawaiian, Pacific Islander & $20(2.6 \%)$ & $27(2.6 \%)$ \\
\hline Black or African American & $89(11.6 \%)$ & $86(8.2 \%)$ \\
\hline Caucasian-American & $616(80.6 \%)$ & $893(84.9 \%)$ \\
\hline Multiple & $23(3.0 \%)$ & $28(2.7 \%)$ \\
\hline Other & $8(1.0 \%)$ & $8(0.8 \%)$ \\
\hline Unknown & $6(0.8 \%)$ & $6(0.6 \%)$ \\
\hline \multicolumn{3}{|l|}{ Ethnicity } \\
\hline Not Hispanic or Latino & $742(97.1 \%)$ & $1,025(97.4 \%)$ \\
\hline Hispanic or Latino & $15(2.0 \%)$ & $20(1.9 \%)$ \\
\hline Don't Know & $7(0.9 \%)$ & $7(0.7 \%)$ \\
\hline \multicolumn{3}{|l|}{ Age at first vaccination (months) } \\
\hline $\mathrm{N}$ & 764 & 1,052 \\
\hline Mean (SD) & $21.5(24.7)$ & $20.2(21.2)$ \\
\hline Median & 15.0 & 15.0 \\
\hline Q1, Q3 & $15.0,16.0$ & $15.0,16.0$ \\
\hline Range & $(11.0-181.0)$ & $(11.0-185.0)$ \\
\hline \multicolumn{3}{|l|}{ Age at second vaccination (years) } \\
\hline$N$ & 764 & 1,052 \\
\hline Mean (SD) & $7.3(3.3)$ & $8.4(3.5)$ \\
\hline Median & 5.0 & 9.0 \\
\hline Q1, Q3 & $4.0,11.0$ & $5.0,12.0$ \\
\hline Range & $(1.0-15.0)$ & $(1.0-17.0)$ \\
\hline \multicolumn{3}{|c|}{ Time from second vaccination to enrollment (years) } \\
\hline $\mathrm{N}$ & 764 & 1,052 \\
\hline Mean (SD) & $7.5(2.7)$ & $6.7(2.9)$ \\
\hline Median & 7.4 & 6.4 \\
\hline Q1, Q3 & $5.6,9.2$ & $4.6,8.6$ \\
\hline Range & $(0.4-16.8)$ & $(0.4-16.8)$ \\
\hline \multicolumn{3}{|l|}{ Immune measure } \\
\hline \multicolumn{3}{|l|}{ Neutralizing antibody $\left(\mathrm{NT}_{50}\right)$} \\
\hline$N$ & 763 & 1,042 \\
\hline Mean (SD) & $1,263.9(1,158.4)$ & $82.3(124.5)$ \\
\hline Median & 844.0 & 57.4 \\
\hline Q1, Q3 & $418.0,1,752.0$ & $34.9,95.8$ \\
\hline
\end{tabular}




\begin{tabular}{|c|c|c|}
\hline & Measles vaccine study $(N=764)$ & Rubella vaccine study $(N=1,052)$ \\
\hline Range & $(45.0-7,723.0)$ & $(17.0-2,391.2)$ \\
\hline \multicolumn{3}{|l|}{ IL-6 (ng/ $\mu \mathrm{l})$} \\
\hline$N$ & 756 & 1,001 \\
\hline Mean (SD) & $362.5(170.6)$ & $3,436.8(906.8)$ \\
\hline Median & 354.6 & $3,595.6$ \\
\hline Q1, Q3 & $248.5,461.4$ & $3,032.0,4,008.4$ \\
\hline Range & $(-163.7$ to $1,053.6)$ & ( -957.3 to $5,831.8)$ \\
\hline \multicolumn{3}{|l|}{$\operatorname{IFNg}(\mathrm{ng} / \mu \mathrm{l})$} \\
\hline$N$ & 756 & 982 \\
\hline Mean (SD) & $95.6(97.1)$ & $24.3(69.6)$ \\
\hline Median & 67.4 & 6.2 \\
\hline Q1, Q3 & $35.2,120.5$ & $1.5,20.2$ \\
\hline Range & $(-211.9$ to 623.5$)$ & $(-239.0$ to 579.4$)$ \\
\hline
\end{tabular}

$S D$ standard deviation, $Q 1$ first quartile, $Q 3$ third quartile, $N T 50$ neutralizing titer, $I L$ interleukin, $I F N$ interferon 


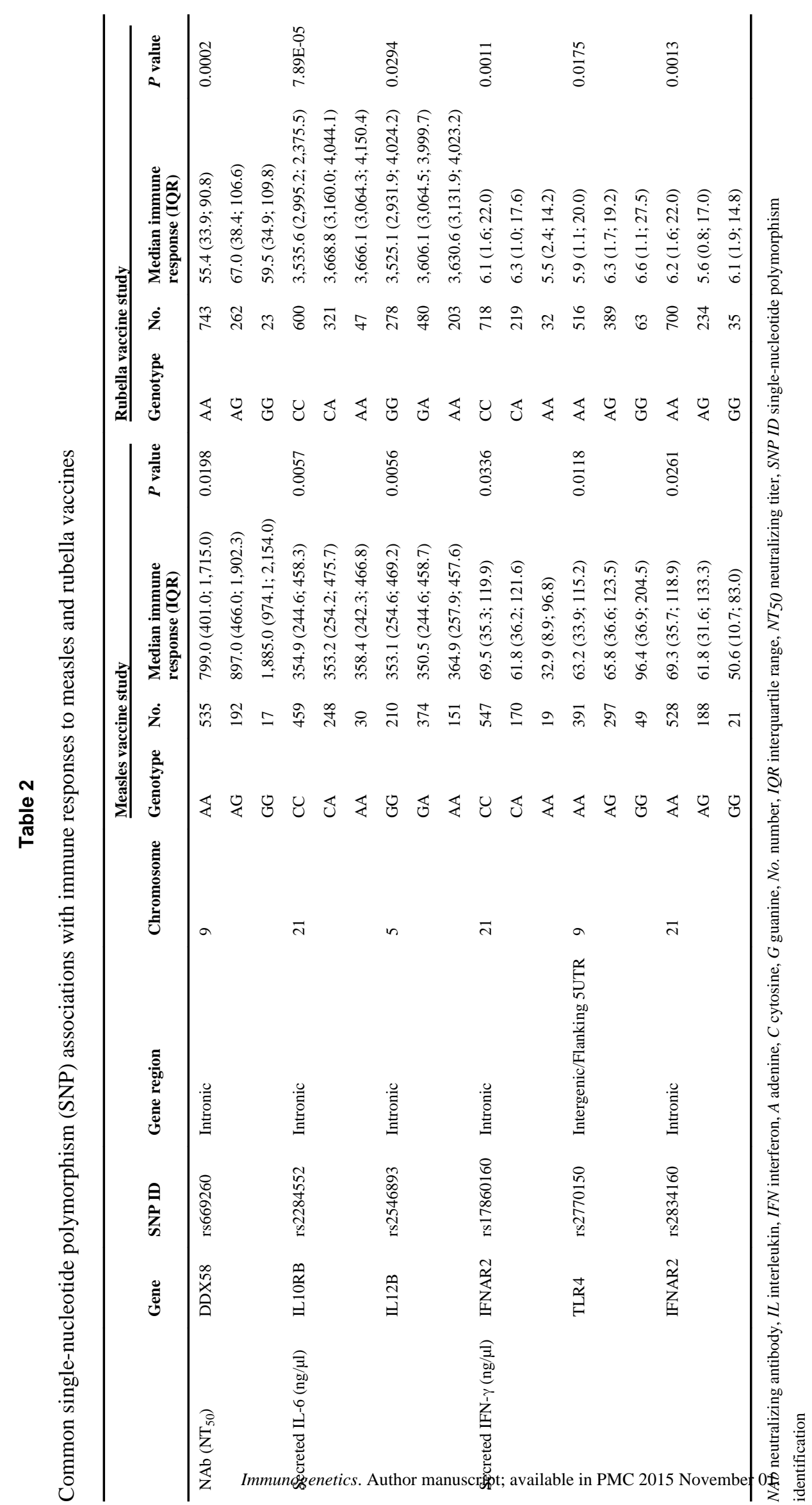

